1. COMENTARIO MONOGRAFICO

\title{
LA FALTA DE PREVISION DE LOS RECURSOS FINANCIEROS PRECISOS PARA HACER EFECTIVOS LOS PAGOS DE OBRAS CONTRATADAS POR UN AYUNTAMIENTO, PUEDE DAR LUGAR A DECLARARLE INCURSO EN CAUSA DE RESOLUCION DE CONTRATO, OBLIGANDOLE A INDEMNIZAR DAÑOS Y PERJUICIOS
}

$352.712: 340.142$

por

\section{Nemesio Rodríguez Moro}

Esta es la tesis que sustenta el Tribunal Supremo (Sala 4..$^{\mathrm{a}}$ ) en su sentencia de 22 de mayo de 1976 (Ar. 3.994), donde, después de analizar la actuación de la Corporación municipal y la del contratista de obras, estimó que debe imputarse solamente a la Corporación el incumplimiento del contrato, que obligaba a ambas partes contratantes a cumplir sus respectivas obligaciones.

Los antecedentes fácticos del caso son los siguientes:

1. El Ayuntamiento en cuestión sacó a concurso-subasta la construcción de dos grupos de viviendas, uno de 44 y otro de 12 , haciéndose constar en la escritura otorgada al efecto que el pago quedaba subordinado a la aprobación por los órganos correspondientes del Ministerio de Hacienda del presupuesto extraordinario que ya se estaba tramitando.

2. Como el Ayuntamiento no puso en su debido tiempo a disposición del contratista el solar sobre el que se habían de levantar las 12 viviendas, $\mathrm{y}$, por otra parte, demoró excesivamente el pago de las varias certificaciones de obra presentadas por el contratista, no haciéndose efectivas más que algunas de dichas certificaciones por no disponer del numerario suficiente, el contratista tuvo que demorar el inicio del mencionado grupo de 12 viviendas, y así bien hubo de suspender y paralizar las obras del otro grupo al agotar sus medios financieros, lo cual indujo al Ayuntamiento a declarar la rescisión, en realidad resolución, del contrato, haciendo responsable al contratista de los daños y perjuicios por el retraso, imponiéndole la continuación de las obras hasta su terminación. 
3. El contratista recurrió en reposición contra el acuerdo municipal, reposición que fue desestimada por la Corporación municipal, formulándose por el contratista en tiempo recurso contencioso-administrativo ante la Sala correspondiente de la Audiencia Territorial de Valencia, la cual dictó sentencia con fecha 5 de noviembre de 1969, cuya parte dispositiva decía así:

«Fallamos que, estimando en parte la excepción de inadmisibilidad alegada por el Abogado del Estado, desestimando dicha inadmisibilidad respecto a la pretensión resolutoria del contrato actuado por la sociedad recurrente en el presente recurso instado por dicha sociedad contra los acuerdos plenarios del Ayuntamiento de 28 de octubre y 10 de diciembre de 1968 y estimando en parte el recurso, declaramos que dichos acuerdos que anulamos son contrarios a derecho; y en cuanto no han sido estimadas las excepciones y las pretensiones de la sociedad reclamante no afectadas por la excepción, deben de tenerse por desestimadas y la Administración absuelta, sin costas».

Promovidas apelaciones por el Abogado del Estado y sociedad recurrente, el Tribunal Supremo dicta sentencia desestimando la apelación del Abogado y estimando la de la sociedad recurrente, revoca la sentencia impugnada y declara: «1. ${ }^{\circ} \mathrm{La}$ anulación por ser contrarios al ordenamiento jurídico, dejándolos sin valor ni efecto, de los conjugados acuerdos municipales a que se ha hecho referencia. 2. Declaramos resuelto el contrato entre el Ayuntamiento demandado y la sociedad accionante para la construcción de los dos grupos de viviendas de renta limitada subvencionadas de anterior cita, por incumplimiento de la Corporación. $3 .^{\circ}$ Condenamos al referido Ayuntamiento a indèmnizar a la sociedad recurrente en los daños y perjuicios que le ocasionó el mencionado incumplimiento por el impago parcial de la obra realizada y consiguiente inmovilización de numerario, según liquidación que se practicará en fase de ejecución de sentencia. Confirmando la (sentencia) apelada en cuanto coincide con los anteriores pronunciamientos y revocándose en el resto".

En la sentencia a que se refiere la anterior resolución del Tribunal Supremo se plantean y resuelven cuestiones varias, algunas de ellas de indudable interés, que se apuntan de modo sintético seguidamente.

A) El Ayuntamiento obró con imprevisión y negligencia al lanzarse a una promoción de viviendas careciendo de los recursos fi- 
nancieros que exige al efecto el número 2 del artículo 25 del Reglamento de Contratación de las Corporaciones locales, sin que pueda aceptarse como bastante el acuerdo de formación de un presupuesto extraordinario, cuando de antemano se sabía que no sería posible hacer frente a los pagos de las obras que se efectuasen al no contar con los ingresos precisos para ello.

B) Si la Corporación no pudo poner a disposición del contratista el solar en que había de construirse el grupo de las 12 viviendas, sólo a dicha Corporación es imputable la imposibilidad en que el contratista se encontró de iniciar a su tiempo la edificación de las mismas.

$\mathrm{Y}$ estas razones fundamentales, expuestas con amplitud de razonamientos en los considerandos correspondientes, son las que conducen al Tribunal a estimar que la Corporación municipal es la única responsable del incumplimiento del contrato, siendo, por tanto, de su cargo los daños y perjuicios causados al contratista por tal actuación.

C) Otra cuestión de gran interés es la de si el contrato en cuestión debe considerarse como de naturaleza civil o administrativa. Y después de una extensa incursión al campo de la teoría de los actos separables, con referencia a la regulación en nuestro Derecho positivo y a la aplicación que del Reglamento de Contratos del Estado se ha hecho en esta materia por la jurisprudencia al Dérecho local, viene a sentar la conclusión de que, si bien en términos generales puede considerarse de carácter civil la construcción de viviendas por un Ayuntamiento, sin embargo ha de estimarse que el contrato objeto del litigio tiene naturaleza administrativa por el acusado relieve que el interés público tiene en ello, que lo hace asimilable a aquellos que tienen por objeto y finalidad obras y servicios públicos, típica y unitariamente sujetos a la Jurisdicción contencioso-administrativa.

Para que pueda conocerse en toda su amplitud y pormenores el desarrollo argumental del razonamiento del Tribunal Supremo, se transcriben íntegramente los considerandos de la sentencia objeto de comentario, los cuales son del tenor literal siguiente:

Considerando: Que no es posible escindir la unidad de contenido de la instancia jurisdiccional, acudiendo para ello a la inadmisibilidad parcial del recurso, cuando la pretensión contenciosa versa sobre acto administrativo que declara la resolución, bien que llamándola rescisión, de un contrato que también la parte recurrente solicita se declare 
resuelto, y la materia procesal se concreta ya a limine en quién de los contratantes es culpable del incumplimiento con los derivados efectos indemnizatorios y de otra clase de dicha alternativa en cuanto a la culpabilidad pueden seguirse, por lo cual, si se aplica la incompetencia de jurisdicción como causa de inadmisibilidad limitada a la pretensión resolutoria del demandante, se viene con ello a entrar y resolver, que aquí es lo mismo que prejuzgar, sobre el fondo del asunto, es decir, sobre fundamentos de las resoluciones impugnadas que implican examen de su ajuste a derecho, lo que en mayor grado aún ocurre si aquella causa se opone a la admisión del entero recurso, ya que el representante de la Administración la fundamenta en el artículo 82, apartado a), de la Ley jurisdiccional, pero con base en una incompetencia de jurisdicción que deduce de la doctrina de los actos separables, convirtiendo asi en supuesto lo que para el caso es cuestión por cuanto que los recurridos actos no la aplican, y, al contrario, invocan como fundamento la competencia administrativa para resolver - rescindir- el contrato, evidenciándose así que el referido problema de competencia, como subordinado al de aplicación de la apuntada doctrina de los actos separables, es aquí cuestión de fondo, inidónea de suyo para amparar la alegada causa de inadmisibilidad, que, tanto con parcial efecto sobre la concreta pretensión resolutoria, como en modo omnicomprensivo sobre el recurso, debe en su virtud desestimarse.

CONSIDERANDo: Que tampoco la inadmisibilidad parcial puede fundarse en una supuesta carencia de acto administrativo previo y autóno. mo que decidiera la pretensión resolutoria del contrato ejercitada en vía procedimental mediante escrito de 6 de septiembre de 1968 presentado por la sociedad hoy recurrente al Ayuntamiento, pues dicha solicitud quedó expresamente resuelta y desestimada por los actos que aquí se impugnan como así procede estimar teniendo en cuenta las siguientes razones: $1 .^{\mathrm{a}}$ Porque fue incorporada al expediente administrativo a través del escrito de alegaciones deducido en el mismo con cita expresa, $y$, por este cauce, se examina y rechaza en la séptima de las consideraciones del acuerdo aquí combatido de 28 de octubre de 1968; 2.a Porque dicha pretensión resolutoria y el escrito en que se formuló de 6 de septiembre de 1968 fueron de nuevo aducidos e invocados en el recurso de reposición interpuesto contra el susodicho acuerdo; 3. a Porque el escrito en cuestión versaba sobre la misma materia contractual que era objeto del expediente abierto el día anterior por el Alcalde, y era la sociedad presentante la única interesada en el procedimiento contra ella dirigido, y $4 .^{\text {a }}$ Porque la radical incompatibilidad con los pronunciamientos contenidos en el acuerdo de la Corporación, necesariamente implicaba la desestimación de aquella anterior solicitud. Razones que impiden reputar independiente la pretensión resolutoria reproducida en la demanda del ámbito expediental afectado por los actos recurridos y que de éstos constituye su presupuesto procesal, a lo que cumple añadir que una aceptación de la referida independencia de pretensiones representaría desarticular la unidad de materia del actual 
proceso, donde la petición resolutoria se configura como consecuencia de la postulada anulación de los acuerdos impugnados, es decir, al amparo del artículo $84, b$ ), de la Ley jurisdiccional como cuestión de fondo también vinculada a la de competencia de jurisdicción, que, como ya se ha dicho, pertenece aquí al fondo del asunto en cuanto concerniente a dilucidar si es o no al caso aplicable la doctrina de los actos separados, tema a su vez supeditado al de la naturaleza civil o administrativa que corresponda asignar al contrato motivador de los debates actuales.

Considerando: Que la calificación de los contratos no depende del arbitrio de las partes, sino de la condición de las mismas y significado del objeto y causa, según los preeminentes criterios legales interpretados por el juzgador, sin vinculación alguna a la nomenclatura calificadora dada por los contratantes; y siendo la naturaleza del contrato lo que determina la jurisdicción, la sentencia recurrida califica a estos efectos de civil el celebrado por el Ayuntamiento con la sociedad recurrente para la construcción de grupos de viviendas de renta limitada sin apreciar las circunstancias que pudiesen ponderarse como relevantes en orden a variar la expresa calificación, y como quiera que la resolución de aquel contrarto, consignada en el acuerdo impugnado como rescisión, no es acto separable de índole procedimental, resultase consecuencia de esa tesis la disconformidad con el ordenamiento jurídico de dicho acuerdo de la Corporación que reputa administrativo y no civil el contrato, sobre lo cual cumple observar que la doctrina de los actos separables, expresamente acogida en el artículo 13 del Reglamento de 28 de diciembre de 1967, para la aplicación de la Ley de Contratos del Estado, había sido extendida por la jurisprudencia a la esfera de la Administración local (sentencias de esta Sala de 19 de enero de 1959, 17 de octubre de 1961, 27 de diciembre de 1963 y 16 de marzo de 1964, y con el mismo criterio las de 10 de diciembre de 1968, 7 de marzo de 1969 y 28 de octubre de 1972, entre otras), en el sentido de atribuir a la Jurisdicción contencioso-administrativa aquellos actos cuyo significado y alcance se agotan en el ámbito procedimental del reglado modo de formación de la voluntad del órgano administrativo contratante, doctrina ya por sí de marcada praxis casuística, toda vez que el general criterio que establece no es siempre indicador preciso de los límites jurisdiccionales de actos en sí integrados en una totalidad contractual que viene a quedar distribuida entre dos jurisdicciones, y así, en su concreta proyección sobre el presente caso, la doctrina en cuestión, invocada en la sentencia recurrida, implica una calificación civil del contrato que en aquella sentencia se tiene por inconcusa reputándolo ajeno a las obras y servicios públicos determinantes de la calificación de administrativo, y si bien en términos generales dicho carácter civil es el de pertinente asignación a los contratos de construcción de viviendas de renta limitada de que es promotor el Ayuntamiento contratante, no resulta ello incompatible con la unitaria inclusión en el ámbito administrativo de especiales supuestos en que se acredite, como en el caso actual ocurre, el peculiar relieve en el Muni- 
cipio de la necesidad de promocionarse por la Corporación construcciones de viviendas sin otros fines que los públicos ligados a preeminentes atenciones sociales para la comunidad municipal, con lo que así incorporado al elemento causal del contrato, tercero de los requeridos para su existencia en el artículo $10^{\circ}$ del Reglamento de Contrataciones, el fin público de anterior mención, la factible comprensión del mismo en el artículo 101, apartado $k$ ), en relación con el $g$ ) de la Ley de Régimen local, hace necesario asimilar en naturaleza y significado el especial contrato que se examina a los de obras y servicios públicos, típica y unitariamente sujetos a la Jurisdicción contencioso-administrativa, máxime cuando el artículo $3 .^{\circ}, a$ ), de la Ley que la regula extiende a "toda especie» de obras y servicios públicos la contratación subsumible en su ámbito, factor amplificante de la estricta acepción de obras y servicios públicos que permite la asimilación del contrato aquí contemplado a los que son públicos por su referido objeto y finalidad a efectos de integración en el orden administrativo y consecuente tratamiento por la Jurisdicción contencioso-administrativa; hermenéutica esta que es coherente con la que, en el distinto plano de las relaciones de los contratantes con la Administración central, ha impuesto la reglamentación sobre viviendas protegidas, que llega incluso, aun siendo en esencia inderogable la competencia jurisdiccional, a exigir expresa sumisión al orden administrativo y contencioso-administrativo en la contratación de obras de viviendas de renta limitada, según de modo expreso se establece en la condición 26 de la Orden del Instituto Nacional de la Vivienda de 21 de febrero de 1956, Boletín Oficial del Estado de 30 de agosto, reflejo de la progresiva tendencia a evitar la dualidad de jurisdicciones a que conduce la doctrina de los actos separables y cumplir la contencioso-administrativa, fines y garantías idénticos a la civil en estos casos especiales, donde el interés público no es de posible desarraigo y aislamiento en todo el proceso de génesis, perfección y cumplimiento contractual, y que de suyo requieren un trato integrativo pertinente a este ámbito de la jurisdicción.

Considerando: Que así definido el carácter público-administrativo del contrato de autos, preciso es entrar de lleno en la cuestión básica del recurso centrada en el tema de cuál de las partes incumplió el contrato en términos que impliquen culpabilidad determinante de resarcimiento, problema sobre el que previamente cumple denotar, según se desprende de las actuaciones procedimentales, que el Ayuntamiento se lanzó a una promoción de viviendas careciendo de los recursos financieros que exige el artículo 25, número 2, del Reglamento de Contrataciones de 9 de enero de 1953, sin que al presente caso resulte aplicable el genérico principio de que basta para contratar las obras el acuerdo de formación de su presupuesto extraordinario, ya que tal proyecto financiero no es ni puede ser, a tenor de los artículos 695 y 709 de la Ley de Régimen local, mera oficialidad ficticia en cuanto a los ingresos reales con que la Corporación podría contar para el cumplimiento de sus obligaciones de pago al contratista, toda vez que prácticamente, 
como así lo acreditan los posteriores hechos, sólo existían posibilidades, y ello aún pendiente de trámite, de las respectivas subvenciones del Ministerio de la Vivienda, muy inferiores a los totales pagos que el Ayuntamiento habría de afrontar; y a esta imprevisión o negligencia municipal, que descansaba en que el contratista ante la oficial formación de presupuesto habría de continuar la obra aun sin pagarle, debe añadirse que tampoco cuidó la Corporación de adecuar el terreno o solar correspondiente al grupo de 12 viviendas para hacer en él viable el proyecto de construcción que, a pesar de todo ello, contrató, estableciéndose plazos de ejecución de las obras forzados por su necesaria concordancia con los que la Corporación había señalado en los trámites. ante los organismos del Ministerio de la Vivienda para conseguir los beneficios de la protección estatal, pero que el Ayuntamiento, al no cumplir con la puesta a punto del solar adecuado al proyecto del grupo de 12, hizo para éste inviable incluso el inicio de la obra, mientras que comenzada y avanzada la construcción con respecto al otro grupo de 32 viviendas, tan pronto resultó ello posible en armonía con las gestiones municipales sobre calificación provisional, fueron cinco las certificaciones de obra realizada que sucesivamente presentó al cobro la sociedad contratista, y la expresada carencia de recursos financieros por parte de la Corporación impidió el pago hasta que muchos meses después de presentadas las dos primeras pudo sufragar tan sólo éstas por medio de las subvenciones entonces obtenidas del Ministerio de la Vivienda, pero con imposibilidad de pagar las certificaciones posteriores ante el descuido municipal relativo al presupuesto extraordinario, que, formalmente iniciado, incluía previsiones hipotéticas, irreales e insuficientes que de modo necesario y a limine habrían de conducir al impago, como así ocurrió, ocasionando el agotamiento financiero de la sociedad constructora hasta hacer que a la misma le fuese imposible continuar las obras; antecedentes que excluyen la aplicación al caso del artículo 56 del Reglamento de Contrataciones de 1953 por cuanto que faltó la base de actuación del expresado precepto, o sea, la previsión por el Ayuntamiento de reales y hacederos recursos, que no es lo mismo que vacías actuaciones formales, en cuanto a lo que a la Corporación exige en el artículo 25, 2, del citado cuerpo reglamentario en relación con el 695 de la Ley de Régimen local, sin que el reconocido interés público y social fundante de las obras y la apremiante necesidad de estas nuevas viviendas en el Municipio puedan justificar, a costa de la contratista, la carencia de los virtuales y bastantes recursos para promocionar las obras mediante el contrato examinado.

Considerando: Que, en su virtud, el incumplimiento contractual como actuación antijurídica sólo debe imputarse a la Corporación, sin que, dentro de la común voluntad de las partes de resolver el contrato, resulten operantes las tentativas de desplazar causalmente aquella imputación de antijuridicidad hacia la sociedad contratista con el consiguiente enriquecimiento injusto que ello provocaría a favor del Ayuntamiento, siendo aspecto relevante de las susodichas tentativas la exigencia 
hecha a la sociedad hoy recurrente de fianza hipotecaria cuando era la Corporación quien no pagaba las certificaciones de obra realizada y tenía conocimiento de que la sociedad constructora no poseía bienes inmuebles, condición de titularidad tabular a la que el artículo 86 en relación con el 165,5 , de la Ley Hipotecaria supedita el uso por la Administración contratante de la facultad de imponer tal clase de fianza complementaria.

CoNSIDERANDO: Que en las referidas circunstancias, al declarar los actos impugnados la rescisión del contrato y decretar contra la contratista -con sus derivadas-, las medidas del artículo 97 en relación con los 65 y 67 del Reglamento de Contrataciones, aplicó indebidamente los citados preceptos, vulnerando también aquellos actos el artículo 66, 1, del mismo Reglamento en cuanto que, a su tenor, y de conformidad con las conclusiones anteriormente establecidas, el acuerdo procedente era el de resolver el contrato, pero por incumplimiento de la Corporación; lo que a la vez que obliga a estimar el recurso y anular los impugnados actos a tenor de los artículos 83, 2, y 84, a), de la Ley jurisdiccional induce a declarar resuelto el contrato por incumplimiento del órgano municipal, estimándose así en su esencia la correspondiente pretensión de la demanda conforme al artículo $84, b$ ), de dicha Ley reguladora de la Jurisdicción.

CoNSIDERANDo: Que la actuación negligente del Ayuntamiento a que ya se ha hecho referencia cualifica como culpable la imputación al mismo del incumplimiento contractual, lo que, de acuerdo con el artículo 92 del Reglamento de 9 de enero de 1953, hace a la Administración municipal responsable del resarcimiento de eventum damni, cuya realidad es manifiesta sin más que observar la obra efectuada y el sólo parcial pago que obtuvo la accionante con los demás perjuicios propios de esta inmovilización de numerario, cuya total indemnización no trae ya su causa en el título contractual en cuanto que fuente de obligaciones aquí declarada resulta ineficaz, sino que obtiene su directo fundamento en la Ley a través del precepto antecitado, que es trasunto administrativo del general principio acogido en el artículo 1.124 en relación con el 1.101 del Código civil, con especificación cuantitativa del susodicho resarcimiento a efectos procesales mediante su fijación en período de ejecución de sentencia, como previene el artículo 84, c), de la Ley jurisdiccional y en congruento pronunciamiento con la pretensión al respecto contenida en la súplica de la demanda.

ConsIDERANDo: Que estimado así el recurso contencioso y pretensiones deducidas al formalizarse el mismo, cumple revocar en parte la sentencia apelada por cuanto que sus pronunciamientos sólo coinciden con los aquí adoptados en la anulación de los actos administrativos objeto de la instancia jurisdiccional, procediendo en su virtud desestimar el recurso de apelación promovido en nombre de la Administración demandada y sin expresa condena en las costas de ambas instancias ante esta jurisdicción por no apreciarse motivos de los enumerados en el artículo 131, 1, de la Ley que la regula. 


\section{RESEÑA DE SENTENCIAS}

SUMARIO: I. ACTO ADMINISTRATIVO: 1. EJeCUTIVIDAD. 2. Actos NULOS Y ANULABLeS.-II. BIENES: 1. AUTORIZACIÓN MUNICIPAL a PRECARio para ocupar el SUbSuelo vial CON Red eléctrica. 2. Camino RURAL: RECUPERACION ADMINISTRATIVA. 3. RECUPERACION ADMINISTRATIVA.-III. CONCESIONES: MARISMAS: TRANSFORMACIÓN EN TERRENOS DE PROPIEDAD PRIVADA.-IV CONTRATACION: 1. CONCURSO PARA EL TRANSPORTE DE VIAJEROS: ADJUDICACIÓN AL MEJOR POSTOR. 2. FALTA DE PERSONALIDAD DE SOCIEDAD NO CONSTITUIDA LEgalMENTE. 3. CONTRATO DE VENTA DE BIENES DE UN AYUNTAMIENTO CON LA OBLIGACIÓN DE EDIFICAR. - V. EXPROPIACION FORZOSA: 1. JUSTIPRECIO: PREMIO DE AFECCIÓN. 2. JUSTIPRECIO: SOLAR: VALOR DEL INDICE DE PLUSVALfA. 3. LOCAL DE NEGOCIO: CONCEPTOS A INDEMNIZAR.-VI. FUNCIONARIOS: 1. CONCURSOS DE INTERVENTORES: MODIFICACIÓN DE NOMBRAMIENTO PROVISIONAL. 2. CONCURSOS Y OPOSICIONES: NATURALEZA DE LA CONVOCATOria. 3. Concursos: Secretarios: IMPUgnación de las bases. 4. Clases pasivas: actualización de pensiones. 5. Clases pasivas: pensión de ORFANDAD ANTERIOR A LA ENTRADA EN VIGOR DE LA LEY 108/1963: CóMPUto de ouinguenios. 6. Clases pasivas: nacionalidad española. 7. ClaSES PASIVAS: JUBILACIÓN: CÓMPUTO DEL Df́a EN QUE SE CUMPLEN LOS AÑOS. 8. Clases pasivas: Jubilación: Servicios interinos. 9. Secretarios: obligatoriedad de llevar la Secretaria del. Juzgado de Paz de menos dE 7.000 H ABITANTES. - VII. HACIENDAS LOCALES: 1. ARbitrio de plusvalfa: eXPlotación agrfCola. 2. CONTRIBUCIONES eSPECiales: COSTO DE LAS OBRAS: INCLUSIÓN DEL IMPORTE DE LAS EXPROPIACIONES. 3. CONTRIBUCIONES ESPECIALES: EXENCION IMPROCEDENTE DEL BANCO HIPOteCaRIO de EsPaña.-VIII. POLICIA MUNICIPAL: 1. Actividades MoLESTAS, INSALUBRES, NOCIVAS Y PELIGROSAS. 2. LICENCIAS: OTORGAMIENTO POR ERROR: DEClaración de NUlidad. 3. Licencias: Obra Sindical del Hogar y arouitectura. 4. Ruina: causas para declararla. 5. RuiNA: CONCEPTO UNITARIO. 6. RUINA: FACULTADES DEL AYUNTAMIENTO Y DE la Fiscalfa de la Vivienda. 7. RUINa inminente.-IX. SEGURIDAD SOCIAL AGRARIA: AYUNTAMIENTOS: EXENCIÓN. - X. TELEFONOS: INSTALACIÓN AÉREA CON POSTES ENCLAVADOS EN VIAS MUNICIPALES: competencia.-Xi. URbanismo: 1. Parcelaciones: Plan Parcial. 2. PROYecto de uRbanización: documentos INTEgRantes del EXPEDIENte. 3. Planes: su obligatoriedad. 


\section{ACTO ADMINISTRATIVO}

\section{EJECUTIVIDAD}

Tenemos que recordar aquí el carácter inmediatamente ejecutivo de los actos administrativos (artículos 33 de la Ley de Régimen jurídico de la Administración del Estado y 44 y 101 de la Ley de Procedimiento administrativo) y, por lo general, salvo que se acuerde la suspensión, la no detención de dicha ejecutividad (arts. 116 de la Ley de Procedimiento administrativo y 122 de la Ley de la Jurisdicción contenciosoadministrativa) por la interposición de recurso. (Sentencia de 11 de octubre de 1976, Ar. 5.079).

\section{ACTOS NULOS Y ANULABLES}

Considerando: Que preciso será partir de ser muy diferente el tratamiento jurídico que a efectos merecen las acciones de nulidad relativa o de simple anulabilidad y las de nulidad absoluta de pleno derecho in radice; mediante las primeras se impugnan actos administrativos que devienen nulos solamente al instante de la declaración de su nulidad por el Tribunal, pero que pueden convertirse en definitivamente válidos y eficaces si tales acciones no se ejercitan en tiempo hábil, ya que normalmente son prescriptibles o caducables, o contra las formalidades, trámites o requisitos exigidos por las Leyes de procedimiento con el carácter de presupuestos procesales; consecuencia de ello es que son más vulnerables en el proceso; ahora bien, tal anulabilidad que, aparte de mirarse siempre con cierto recelo según doctrina jurisprudencial y con carácter restrictivo, la misma sólo sería dable predicar en tanto en cuanto el trámite infringido fuera esencial, ordenado imperativamente por precepto legal y que su omisión hubiese causado la indefensión del administrado, indefensión que constituye el aspecto teleológico de las nulidades finales en Derecho administrativo (artículo 48, número 2, de la Ley de 17 de julio de 1958 y sentencias ad exemplum de 9 de enero de 1963, 29 de septiembre de 1964, 31 de enero de 1966, 28 de febrero de 1967, 6 de junio de 1973 y 9 de junio último); contrariamente, la nulidad absoluta, radical o de pleno derecho, no es susceptible de subsanación ni de producir efectos jurídicos en ningún tiempo, puede alegarse en cualquier momento y como secuela la acción no tiene plazo de caducidad, es imprescriptible e irrenunciable, particularmente no puede considerársela tácitamente renunciada por la falta de utilización de un trámite o por una situación de aquietamiento y sobre todo es del mayor interés por ser el conocimiento de estas acciones de nulidad cuestiones de interés general y de orden público, tanto si se trata de actos sustantivos como de procedimiento cuando inciden en cualquiera de los vicios comprendidos en los apartados $a$ ), b) y $c$ ) del párrafo $10^{\circ}$ del ar- 
tículo 47 de la calendada Ley procedimental; siendo también de apreciación de oficio en cualquier momento, y de concurrir esta última clase de nulidad plena, goza de preferente examen, y tratándose del contenido que encierra el invocado apartado $c$ ), para que éste se dé es necesario «se prescinda total y absolutamente del procedimiento establecido para ello", expresión pleonástica que sólo consiente la invalidez plena del acto, cuando concurra la carencia entera y completa de los trámites procesales señalados para su producción, con lo que tampoco basta a la configuración de la Ley cualquier defecto u omisión parciales de lo normado (sentencias, entre otras, de 7 de marzo de 1963, 3 de noviembre de 1964 y 9 de junio de 1976, etc.). (Sentencia de 11 de octubre de 1976, Ar. 5.125).

\section{BIENES}

1. AUTORIZACIÓN MUNICIPAL A PRECARIO PARA OCUPAR EL SUbSUELO VIAL CON RED ELÉCTRICA

No existen términos hábiles que permitan sostener la validez de esa cláusula de precariedad impuesta por el Municipio en la licencia otorgada a la sociedad demandante, ya que a la luz del artículo 7.० de la Ley de 18 de marzo de 1966, antes citada, y del 29 de su Reglamento de aplicación muéstrase con absoluta claridad cómo a la facultad administrativa de imponer la variación del tendido cuando por consecuencia de planes o proyectos debidamente aprobados ello fuese necesario, de suerte que así quede asegurado el mantenimiento del destino primordial del dominio público ocupado, se contrapone por el Ordenamiento la indemnidad patrimonial del interesado, de modo que sin perjuicio del imperium y prerrogativa inherentes a la Administración en cuanto titular del interés público que demanda la alteración de la línea eléctrica, esta modificación de la situación existente que nació en virtud de un acto administrativo autorizante no apareja para su titular una lesión patrimonial que aparecería en radical contradicción con los principios fundamentales rectores de la responsabilidad administrativa, los cuales anudan la consecuencia de la indemnización incluso a los hechos dañosos derivados del funcionamiento normal y de la regular actividad de la Administración -y de la revocabilidad o rectificabilidad de las licencias - que comportan naturalmente el correspondiente resarcimiento. (Sentencia de 8 de octubre de 1976, Ar. 4.987).

\section{CAMINO RURAL: RECUPERACIÓN ADMINISTRATIVA}

Considerando: Que, partiendo, pues, de la realidad inconcusa de un bien de uso público municipal (artículos 344 del Código civil, 184 de la Ley de Régimen local y $30^{\circ}$ del Reglamento de Bienes de las Entidades 
locales de 27 de mayo de 1955), es igualmente incuestionable la competencia de la autoridad municipal para vigilar y defender su libre tránsito común, como atribución propia expresamente consignada en los apartados a) y $h$ ) del artículo 101 de la Ley - vías públicas rurales y policía rural一: "La policía de los caminos rurales corresponde a los Ayuntamientos, dentro de sus respectivos términos, y en ella están comprendidas las medidas necesarias para mantenerlos abiertos al libre tránsito vecinal, atendida su indiscutible condición de bienes de uso público» (sentencia del Tribunal Supremo de 30 de octubre de 1965); no estando sometida su recuperación posesoria a plazo alguno de caducidad o prescripción, ya que, por tratarse de bienes imprescriptibles, la medida recuperatoria puede verificarse en cualquier tiempo (artículo 55, número 1, del Reglamento) sin necesidad de sujetarse al plazo de un año, que solamente es aplicable a los bienes patrimoniales del Municipio (artículo 55, número 2). (Sentencia de 25 de mayo de 1976, Ar. 3.005).

\section{RECUPERACIÓN ADMINISTRATIVA}

CONSIDERANDO: Que la recuperación administrativa de bienes, como una forma de autotutela equivalente al interdicto, exige para su éxito la demostración de la posesión por el Ente actuante y de la usurpación del uso por el particular, que es lo que el apartado $3 .^{\circ}$ del artículo 55 del Reglamento de Bienes pretende al exigir, "salvo qe se tratare de repeler usurpaciones recientes", que se acompañen al acuerdo municipal los documentos acreditativos de la posesión; y si bien es cierto que en aquellos casos puede ser posible prescindir de la demostración documental, no así de la prueba suficiente de la posesión y del despojo; mas en el caso de bienes de uso público, como las calles (que sería el caso aquí), una prueba patente de la posesión viene suministrada por la afectación al uso público que suele patentizarse mediante los signos aparentes de la existencia de la vía y los de su uso colectivo, siendo estos últimos los que en el caso faltan, puesto que al no constatarse (como la resolución impugnada afirmaba) la existencia de puerta alguna al callejón que revelase el paso por éste a finca distinta de la del recurrente ni tampoco que constituyese paso público (en cuanto callejón sin salida) ni mostrar tampoco signo alguno de acción urbanizadora como los existentes en la calle a la que da, ni de policía o entretenimiento municipal, el mero hecho de permanecer abierto a la calle que lo flanquea no puede estimarse prueba bastante del uso público cuando en contra se demuestra a favor del recurrente una presunción posesoria derivada de la inscripción registral de una finca que el propio acto recurrido hace coincidir (al menos en parte) con el citado callejón, al admitir que pueda pertenecer a la casa limítrofe, propiedad del Municipio, y este hecho, contrario al uso público, viene además corroborado por los actos posesorios derivados de que corresponda a la casa de dicho titular la única puerta de acceso existente en el repetido callejón; 
situación en la cual no puede prevalecer la acción recuperatoria municipal y, en consecuencia, procede confirmar la sentencia recurrida en cuanto anuló la resolución impugnada, puesto que el contenido de ésta estaba constituido por una serie de declaraciones y medidas para hacer efectiva la recuperación (orden de demolición del cerramiento, denegación de la licencia para efectuarlo). (Sentencia de 13 de mayo de 1976, Aranzadi 2.707).

\section{CONCESIONES}

\section{MARISMAS: TRANSFORMACIÓN EN TERRENOS DE PROPIEDAD PRIVADA}

Conviene indicar que este tipo de concesión actúa en calidad de título en sentido estrictamente dogmático de una ocupación temporal del terreno saneable (uso privativo) como contenido de un derecho real administrativo de goce que, a su vez, se transforma en propiedad particular mediante la ejecución de las obras de saneamiento, modo de adquirir que implica una desafectación implícita, de tal parcela de dominio público marítimo-terrestre.

Y contra lo que declarado queda, no puede ser óbice lo sustentado en los acuerdos recurridos, puesto que parten, al igual que el informe del Consejo de Estado que sirvió de contenido a los mismos, de la afirmación de ser incompatible la autorización solicitada con la pretendida permanencia del dominio público, en los terrenos litigiosos, habida cuenta que, precisamente, por esa desecación de terrenos pantanosos o de marismas, una vez realizada totalmente, se ha producido una desafectación tácita de esa demanialidad de los terrenos aludidos, conociendo los mismos, desde ese preciso instante, de toda naturaleza pública, pasando de!-dominio público al privado $\mathrm{y}$, en consecuencia, al propio comercio de ic hombres, por lo que no hay matiz público alguno en los terrenos en cu. tión, de ahí que si bien es verdad que la naturaleza demanial de un bier molica, sin otro aditamento, la inalienabilidad, la imprescriptibilidad y incomercialidad del mismo, esas prohibiciones desaparecen cuando y su. cuando el carácter público del mentado bien ha desaparecido, expresa o . itamente, cual ocurre en el supuesto enjuiciado, en el que, en base de esa cecación de la marisma que nos ocupa, los terrenos de la misma perdiero. ' calidad de públicos y se hicieron privados, con todas y cada una de consecuencias. (Sentencia de 10 de noviembre de 1976, Ar. 4.941). 


\section{CONTRATACION}

1. Concurso PARA El SERVICIO DE TRANSPORTE DE VIAJEROS: ADJUDICACIÓN AL MEJOR POSTOR

Como tiene dicho el Tribunal Supremo en su sentencia de 22 de octubre de 1963, el abaratamiento de las tarifas debe ser la regla preferente a la que ha de atender la Administración y no a la selección del contratista, lo cual ni quiere decir que el citado artículo 15 devenga inoperante en la resolución de concursos, sino que la aplicación del mismo tiene carácter subsidiario respecto del 122 del Reglamento de Servicios, y, por tanto, que solamente cuando haya quedado plenamente conseguida la finalidad económica de abaratamiento de tarifas y demás ventajas para los usuarios modestos, deberá la Corporación tomar en cuenta y ponderar las restantes circunstancias que en orden al sujeto y al objeto del contrato hayan sido llevadas al pliego de condiciones. (Sentencia de 22 de junio de 1976, Ar. 4.217).

\section{FAlTA DE PERSONALIdAD DE SOCIEDAD NO CONSTITUIDA LEGALMENTE}

En el caso debatido en este recurso, lo que está en litigio es la personalidad de una sociedad anónima, por lo que habrá que estar a lo que establece su reglamentación específica y concretamente el artículo $6 .^{\circ}$ de la Ley de 17 de junio de 1951 , según el cual la escritura de constitución de la sociedad deberá ser inscrita en el Registro mercantil, desde cuyo momento la sociedad tendrá personalidad jurídica, lo que interpretado a contrario sensu significa que antes de esa inscripción carecía de personalidad jurídica, o sea, de capacidad jurídica y, por tanto, de capacidad de obrar, que exige como presupuesto básico la anterior, por lo cual es evidente que, con arreglo a la Ley de Sociedades Anónimas, el concursante "Ingeniería Urbana, S. A.» sólo la adquirió a partir del día 28 de mayo de 1971, que es cuando su escritura fundacional tuvo acceso al Registro mercantil, por lo que carecía de capacidad jurídica o de obrar por inexistencia de esa inscripción en el momento de presentar sus proposiciones a la Corporación municipal de Murcia, careciendo también de ella por el mismo defecto en el momento de la apertura de proposiciones - 13 de abril de 1971- y en el de la adjudicación definitiva -27 de abril de 1971—, por lo que es evidente que los acuerdos municipales, admitiendo primero la proposición de este contratista, tomando después en cuenta su proposición y por último adjudicándole definitivamente el contrato, son radicalmente nulos por tratarse de actos dictados en contra del Reglamento de Contratación y de la Ley del Contrato o Pliego de Condiciones, y que, por tanto, no pueden ser convalidados ni por la propia Corporación, mediante actos 
posteriores, ni por el silencio que sobre este punto hayan guardado otros contratantes, puesto que los motivos de nulidad no se derivan ni de la aprobación por la Corporación ni de la existencia o inexistencia de recursos interpuestos por otros administrados, sino de la oposición de estos actos a la Ley del concurso, el Reglamento de Contratación y el Ordenamiento jurídico en general. (Sentencia de 13 de junio de 1976, Ar. 4.068).

\section{Contrato de venta de bienes de un Ayuntamiento CON LA OBLIGACIÓN DE EDIFICAR}

No sólo es posible, sino necesario, matizar la tesis invocada en la sentencia objeto de recurso, según cuyo directo sentido bastaría apreciar cualquier fin público de promover la edificación con la venta de bienes de propios para calificar el contrato de administrativo y hacer aplicable al mismo el artículo 65 en relación con el $2 .^{\circ}, 1, c$ ), del Reglamento de Contrataciones de las Corporaciones locales de 9 de enero de 1953, pues, al contrario, y según se desprende de la vinculación a obras y servicios públicos denotada en los artículos $30^{\circ}$ y $4 .^{\circ}$ de dicho Reglamento, conectados con los $5 .^{\circ}, 1$, y 97 del de Bienes de las Entidades locales, la enajenación con causa en precio de inmuebles de propios, aun cuando abstractamente concurrieren motivos de edificación, es en principio y por regla general de índole civil, sujeta la problemática de su resolución a las decisiones de los Tribunales ordinarios, y sólo en supuestos especiales en que la edificación responda a concreta y acreditada necesidad general comprendida en el artículo 101, 2, k), de la Ley de Régimen local, incluyéndose dicho fin público en la causa del contrato como elemento esencial del mismo a tenor del artículo $1 .^{\circ}, c$ ), del Reglamento de 1953 y a través de expresas condiciones señaladas en el pliego correspondiente, cabría entonces subsumir el contrato en la calificación de administrativo dentro de un concepto amplificado de obras y servicios públicos coherente con la extensión a los de «toda especie» hecha para su sujeción a la vía contencioso-administrativa en el artículo $\left.3 .^{\circ}, a\right)$, in fine de la Ley que la regula; todo ello teniendo en cuenta que es la naturaleza del contrato lo que determina la jurisdicción, sin que sea válida la proposición inversa; y como quiera que en el actual supuesto fue causa de la compraventa un fin público típicamente definido en la Ley de Régimen local de anterior cita; consta también en el expediente la necesidad de satisfacerlo en el Municipio, y a ello se condicionó la contratación de modo expreso en sus cláusulas, determinando incluso las de carácter resolutorio y de reversión del inmueble vendido; cumple aquí corroborar la calificación asignada al contrato en la sentencia objeto del recurso, bien que aquél sea por sus características excepción al régimen general de Derecho privado pertinente a los bienes de propios y a su venta no cualificada en los términos antedichos. (Sentencia de 15 de junio de 1976, Ar. 4.106). 


\section{EXPROPIACION FORZOSA}

\section{JUSTIPRECIO: PREMIO DE AFECCIÓN}

ConsIDERANDo: Que con el presente recurso se pretende dar nueva vida a la pretensión de dicha parte de que el premio de afección se aplique a la totalidad de las cantidades que hayan de abonarse al expropiado, sin tener en cuenta que tal tesis ha sido denegada por la sentencia que, al confirmar los acuerdos del Jurado provincial de Expropiaciones, reconoce el 5 por 100 de afección sobre el justiprecio de los bienes expropiados y no hace pronunciamiento alguno sobre tal premio de afección respecto de las indemnizaciones que se conceden por servidumbre de linde, división de la finca y perjuicios causados a la masía porque no les corresponde, siendo interpretación avalada por la jurisprudencia el que el espíritu y la letra del artículo 47 del Reglamento de Expropiación forzosa es el de que tal premio se da sobre el justo precio de la cosa expropiada, pero no sobre los demás conceptos indemnizables, toda vez que lo que en justicia se compensa con el premio de afección es la especial estimación o aprecio que el propietario concede a la cosa, lo que no puede relacionarse con perjuicios ni con ningún otro concepto independiente del estricto valor de la cosa misma. (Aclaración a la sentencia de 22 de octubre de 1976, Ar. 4.951).

\section{JUSTIPRECIO: SOLAR: VALOR DEL INDICE DE PLUSVALfA}

CONSIDERANDO: Que, sentado lo anterior, procede entrar directamente en el examen del problema de fondo objeto de revisión en este proceso y al que necesariamente se contrae la pretensión impugnatoria de la parte actora, de valoración para fijación del justiprecio de la finca expropiada, partiendo para su resolución de que la misma, como resultado probado y admitido en autos, ostenta la naturaleza de solar, edificable de no mediar la expropiación, y que para su tasación la Ley expropiatoria, en su artículo 38, establece con carácter prioritario el criterio estimativo, consistente en el valor que tengan asignado para los efectos del arbitrio municipal sobre incremento del valor de los terrenos, aumentado en un 10 por 100 , y que solamente cuando ese valor fiscal, o el que subsidiariamente señala el mismo artículo 38 , no guarde adecuación con el valor real al que la propia Ley expropiatoria otorga prevalencia, podrá acudirse a los criterios estimativos que se juzguen más adecuados - conforme al artículo 43- para la búsqueda de ese valor real y efectivo, pero correspondiendo la prueba de dicha inadecuación a la parte actora que se alza contra la contraria presunción iuris tantum establecida por el legislador en el susodicho artículo 38, 1 , de la mencionada Ley de Expropiación, conforme todo ello resulta de 
esa normativa legal y ha sido reiteradamente declarado por la jurisprudencia del Tribunal Supremo en sentencias, entre otras, de 28 de noviembre y 16 de mayo de 1968,25 de abril de 1970,2 y 15 de abril y 20 y 23 de octubre de 1971 y 9 de febrero, 3 y 11 de marzo de 1972. (Sentencia de 6 de noviembre de 1976, Ar. 4.606).

\section{LOCAL DE NEGOCIO: CONCEPTOS A INDEMNIZAR}

Considerando: Que refiriéndose en el presente caso la expropiación llevada a efectos por el Ayuntamiento de Málaga para la ampliación de la calle de La Serna, a la privación de los derechos arrendaticios que doña María del P. M. ostentaba sobre una industria de taller de cerrajería y forja, es visto que el justiprecio compensatorio de cese en esa actividad ha de comprender, según enseña la jurisprudencia de esta Sala (sentencias de 25 de febrero de 1971, 29 de septiembre de 1973 y 7 de febrero de 1974), diversos conceptos indemnizatorios, como traspaso o indemnización por mayor renta, gastos de traslado de instalaciones, enseres y mercaderías, pérdida de beneficios durante la inactividad, gastos de personal durante el mismo período, perjuicios derivados de la pérdida de clientela, conceptos que en estos supuestos han de contemplarse para resolver sobre la procedencia de la aplicación de todos o algunos de ellos. (Sentencia de 13 de noviembre de 1976, Ar. 4.818).

\section{FUNCIONARIOS}

\section{CONCURSOS DE INTERVENTORES: MODIFICACIÓN DE NOMBRAMIENTO PROVISIONAL}

Se fundamenta la petición principal en que es nulo el nombramiento de don Angel R. como Interventor de Fondos del Ayuntamiento de Cádiz porque no le fue concedido trámite de audiencia en el recurso de alzada interpuesto por éste contra la resolución del Director general de Administración local de fecha 2 de mayo de 1972, la cual le había nombrado a él con carácter provisional, cuyo recurso fue estimado $\mathrm{y}$, por consecuencia, verificado el nombramiento definitivo de don Angel R. para la plaza de Cádiz; mas este recurso, denominado de alzada por el artículo 199, 2, del Reglamento de Funcionarios de Administración local, según la redacción dada por el Decreto de 20 de mayo de 1958, al dirigirse contra un acto provisional preparatorio del definitivo tiene naturaleza análoga a la reclamación prevista en el artículo 121 de la Ley de Procedimiento administrativo de 17 de julio de 1958, por tanto carente de la consideración de propio recurso, y no requiere en su tramitación con exigencia específica la audiencia de otros interesados, requerida en general por el artículo 91 de dicha Ley de Procedimiento admi- 
nistrativo y por el 296, 2, del Reglamento de Régimen jurídico de las Corporaciones locales de 17 de mayo de 1952, pues las propias normas reguladoras de los artículos 199 a 201 del citado Reglamento de Funcionarios no lo establecen, atendidas precisamente la provisionalidad del acto objeto de la alzada, y en todo caso, que es razón principal, su omisión quedó subsanada por la notificación del acto definitivo y el subsiguiente recurso de reposición, interpuesto contra éste por el actor, excluyéndose así la posible indefensión y con ella el motivo de nulidad regulado por el artículo 48, 2, en relación con el 91, de repetida Ley de Procedimiento, aducidos en la demanda. (Sentencia de 17 de noviembre de 1976, Ar. 4.838).

\section{CONCURSOS Y OPOSICIONES: NATURALEZA DE LA CONVOCATORIA}

Considerando: Que lo primero que debe dejarse aclarado, para resolver correctamente esta cuestión es que las convocatorias de oposiciones y concursos no pertenecen a la categoría de disposición general, sino a la de acto administrativo (sentencias de 21 de diciembre de 1963 y 17 de marzo y 17 de mayo de 1966), aunque no haya faltado alguna sentencia que sentara doctrina contraria (sentencia de 28 de septiembre de 1962) y alguna que otra pronunciándose por la tesis del doble carácter (sentencias de 14 de febrero de 1959 y 14 de marzo de 1966), lo cual es admisible siempre y cuando se deje establecido que la parte esencial de estas convocatorias corresponden a la naturaleza del acto administrativo, puesto que se refieren a una actuación singular y concreta, como es la apertura de un procedimiento selectivo, para la provisión de plaza o plazas vacantes, lo que no es incompatible con la circunstancia de que estos actos se dirijan a una pluralidad de destinatarios, a priori indeterminados, puesto que, aun así, conservan las notas características del verdadero acto administrativo, esto es, su consunción tras de su cumplimiento, su misión instrumental ejecutiva y decisoria y, sobre todo, su discurrir en campo ajeno al ordinamental; doble carácter que, por lo expuesto, sólo se justifica de modo un tanto relativo, en cuanto tales actos contienen unas bases que vienen a desempeñar una función cuasi normativa, en el mismo sentido metafórico con que el Código civil atribuye a las obligaciones que nacen de los contratos fuerza de ley entre las partes contratantes (artículo 1.091), y en el más específico que se predica en el artículo $4 .^{\circ}$ del antiguo Reglamento de Oposiciones y Concursos de 10 de mayo de 1957 y en el artículo $3 .^{\circ}, 2$, del Reglamento vigente, de 27 de junio de 1968. (Sentencia de 21 de junio de 1976, Ar. 2.795). 


\section{CoNCURSOS: SECRETARIOS: IMPUGNACIÓN DE LAS BASES}

Es de plena aplicación en este caso la doctrina jurisprudencial que establece que las bases de la convocatoria constituyen la ley de los concursos, a la que inexorablemente quedan sujetos los que acuden a tomar parte en los mismos, de tal suerte que quienes no formularon oposición a aquéllas quedan privados de todo derecho de impugnar las consecuentes designaciones, caso de ajustarse a tales bases (sentencias de 22 de abril de 1908, 13 de febrero de 1912, 21 de octubre de 1930, 11 de marzo de 1931, 27 de abril de 1935, 10 de junio de 1936, 3 de junio de 1942, 16 de diciembre de 1946 y 17 de marzo y 2 de junio de 1949). (Sentencia de 21 de junio de 1976, Ar. 2.795).

\section{Clases pasivas: actualización de PENSIONES}

Considerando: Que la cuestión debatida en el presente proceso se reduce a determinar si el porcentaje aplicable al sueldo regulador del causante para fijar la pensión ordinaria de viudedad de la recurrente ha de ser el del 45 por 100 fijado por los Estatutos de la Mutualidad Nacional de Previsión de la Administración Local, aprobados por Orden ministerial de 12 de agosto de 1960 , o el 70 por 100 como pretende la actora, de acuerdo con el Reglamento del extinguido Montepío de Funcionarios del Ayuntamiento de Madrid, porcentaje que considera inmutable como derecho adquirido; mas para resolver esta cuestión ha de precisarse previamente que se trata de señalar una pensión actualizada de acuerdo con el Decreto 3.083, de 15 de octubre de 1970, que taxativamente dispone en su artículo $5 .^{\circ}$, párrafo 2 , que sobre el nuevo haber regulador se fijará el porcentaje correspondiente, según las normas estatutarias de la Mutualidad, excluyendo de la actualización las pensiones concedidas al amparo de condiciones más beneficiosas, entre las que expresamente señala la de haber sido aplicado un porcentaje superior al señalado en dichos Estatutos, por lo que la aplicación de tales normas al fijar la pensión de viudedad en un 45 por 100 del haber regulador, que es el porcentaje correspondiente de acuerdo con los Estatutos de la Mutualidad, resulta conforme con las inequívocas disposiciones en el Decreto de actualización de pensiones que se aplica, y sin que ello pueda significar desconocimiento de derechos adquiridos, puesto que si la interesada consideraba más conveniente a sus intereses la aplicación de la normativa anterior a la creación de la Mutualidad, pudo ejercitar la opción que le concede el artículo $2 .^{\circ}$ de dicho Decreto y la resolución de la Dirección General de Administración Local de 2 de diciembre de 1970, que concedió un plazo de treinta días para efectuarla y manifestar que deseaba acogerse al régimen anterior, quedando así excluida de la actualización; lo que no hizo; mas en ningún momento puede pretender que se le aplique la actualización regulada por el De- 
creto $3.083 / 70$ y conservar el porcentaje más elevado que anteriormente pudiera corresponderle, lo que sería contrario a las explícitas normas del referido Decreto. (Sentencia de 3 de noviembre de 1976, Ar. 4.574).

Es muy reiterada la reciente jurisprudencia del Tribunal Supremo en similar sentido al de la sentencia anterior. Así, entre otras, las de 11 de noviembre de 1976 (Ar. 4.811) y 26 de noviembre de 1976 (Ars. 5.103 y 5.108).

Otra sentencia anterior, la de 20 de octubre de 1976 (Ar. 4.256), insiste sobre el mismo tema, y aclara diciendo:

ConsIDERANDo: Que para resolver sobre el fondo litigioso enunciado en el anterior, es preciso poner de relieve que, conforme a lo declarado por esta Sala, a partir de la sentencia de 20 de junio de 1974 y reiterado en las de 21 de octubre del mismo año y 5 y 29 de marzo de 1975, entre otras, obligado es distinguir entre la actualización ajustada al artículo 10 de la Ley 108 de 1963 , de 20 de julio, y la regulada por el Decreto 3.083 de 1970 , de 15 de octubre, cuyas notas diferenciales perfila la propia doctrina de la Sala, declarando que la primera, según la

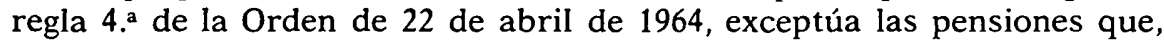
al actualizarlas, resulten superiores o iguales a los nuevos sueldos, mientras que la segunda excluyó de la actualización, en armonía con lo previsto en el Decreto de 19 de diciembre de 1969, las que se hubieren concedido al amparo de condiciones más beneficiosas que resultan de derechos legítimamente adquiridos, con el propósito de mantener la actualización dentro de los límites que la inspira.

\section{Clases Pasivas: PENSION DE ORFANDAD ANTERIOR a la ENTRADA EN VIGOR DE LA LEY 108/1963: CóMPUTO DE QUINQUENIOS}

Considerando: Que la cuestión litigiosa debe decidirse en el mismo sentido de la resolución que dictó el Ministerio de la Gobernación con fecha 23 de julio de 1971, impugnada por la Mutualidad de Funcionarios de la Administración Local; porque es doctrina de la Sala (sentencias, entre otras, de 29 de enero de 1968, 16 de diciembre de 1970, 24 de octubre de 1975 y 13 de mayo del año actual) que, conforme a los artículos $1 .^{\circ}, 2$, y 10, 2, de la Ley 108, de 20 de julio de 1963, y la norma 2.a, 1 , de la Orden del Ministerio de la Gobernación de 22 de abril de 1964, el régimen de quinquenios aplicable a casos como el presente es el establecido por dicha Ley 108, de 1963, y no el vigente en el momento de cesar en el servicio activo el funcionario causante de la pensión, y, por tanto, han de computarse en el cálculo de ésta los quinquenios referentes al tiempo de servicios efectivos, el cual, siendo de treinta y tres años en el supuesto ahora debatido, determina seis quinquenios; man- 
teniéndose así la más justa equiparación entre las situaciones de funcionarios que tengan idénticos años de servicios y de categorías, aun cuando fueren distintas las épocas en que los prestaron, con reflejo, pues, en la igualdad de haberes pasivos. (Sentencia de 12 de junio de 1976, Ar. 2.735).

\section{Clases Pasivas: Nacionalidad española}

ConSIDERANDo: Que la hoy actora, al fallecer su padre, funcionario del Estado, en 3 de octubre de 1915, tenía la naturaleza española, por lo que conforme al número 4 del artículo 83 del Estatuto, puesto que vivía su madre, el derecho que adquirió a pensión de orfandad estaba sujeto a la condición suspensiva de fallecimiento o segundas nupcias de la misma; mas el día 7 de abril de 1970, en que se cumplió esta condición en su primera alternativa, había perdido la nacionalidad española por su matrimonio con un extranjero, contraído en 22 de mayo de 1920 , por lo que no podía cobrar la pensión de orfandad que en otro caso le hubiera correspondido, ya que el artículo 90 del Estatuto de Clases Pasivas dispone que "la condición de español es requisito indispensable para el cobro de todas las pensiones", y esa pérdida del derecho subsiste aun cuando se recuperase la nacionalidad española, como ocurrió en el caso presente, en que la recurrente la recobró en 28 de diciembre de 1970, según acredita la nota marginal de la certificación de su inscripción de nacimiento; pues el artículo 200 del Reglamento, si bien en su primer párrafo dispone que "la condición de español para el cobro de pensiones habrá de ostentarse en el momento del fallecimiento del causante», momento en el que la recurrente era española, en su párrafo 2.. establece que "el que adquiera o recobre la nacionalidad española con posterioridad a dicho momento no tendrá en ningún caso derecho a pensión", y este rigor con que el precepto enjuicia a estos efectos la pérdida de la condición de español se acentúa en un párrafo final al ordenar que "el pensionista que pierda la nacionalidad española perderá también definitivamente el derecho a la pensión"; es decir, que, aunque la recurrente a partir de la muerte del causante hubiera sido titular de un derecho a pensión y no de una mera expectativa o derecho condicionado, la pérdida de tal derecho por un matrimonio con un extranjero tenía carácter definitivo y no le hubiera recobrado al adquirir nuevamente la condición de española, por lo que forzoso es estimar que son conformes a derecho las resoluciones recurridas. (Sentencia de 18 de octubre de 1976, Ar. 4.090). 


\section{Clases pasivas: Jubilación: cómputo del día en que se CUMPLEN LOS AÑOS}

Considerando: Que el error aritmético que se atribuye en la demanda a la certificación municipal de los servicios prestados por el interesado, y al acuerdo de la Comisión permanente de la Corporación reconociéndole el derecho a percibir el noveno quinquenio, no existe en realidad, toda vez que desde el ingreso en el servicio activo, en 9 de septiembre de 1925, y el cese al cumplir la edad de jubilación, el 8 de septiembre de 1970, transcurrieron los cuarenta y cinco años computados por el Ayuntamiento, dado que el día en que cumplió el funcionario de que se trata la edad de jubilación debe considerarse como de servicio a tenor de lo preceptuado en el artículo 37 de los Estatutos de la recurrente, en el $1 .^{\circ}$ del Decreto de 8 de mayo de 1961, número 784, y en el 16, 4, del Reglamento de 13 de agosto de 1966, como lo demuestra que si el "funcionario falleciera antes de cumplir la edad de jubilación forzosa", la Jefatura de personal que estuviere tramitando el expediente de jubilación «lo pondrá en conocimiento de la Dirección General de Clases Pasivas para que se pueda proceder al archivo del expediente iniciado", lo que evidentemente no procede cuando el funcionario fallece el mismo día de cumplir la edad de jubilación forzosa. (Sentencia de 25 de octubre de 1976, Ar. 4.120).

\section{Clases pasivas: Jubilación: SeRvicios interinos}

Considerando: Que si bien con arreglo a lo dispuesto en la Disposición transitoria 2. ${ }^{a}$, párrafo $4^{\circ}$, de los Estatutos de la MUNPAL, a los asegurados obligatorios excepcionalmente se les debe reconocer como período de cotización y afiliación activa todo el tiempo de servicios computables a la Administración local, no es menos cierto que respecto a los jubilados - caso el ahora debatido- a partir del 1 de enero de 1969 debe serles aplicado el artículo 4. ${ }^{\circ}$ del Decreto 3.083/1970, a cuyo tenor tales servicios interinos, abonables a efectos pasivos, correrán a cargo de la Corporación local respectiva en cuanto representen aumento de tales prestaciones; criterio este que ha seguido el Ministerio de la Gobernación al resolver en el acto impugnado en el recurso de alzada interpuesto frente a la decisión al respecto emanada de la $\mathrm{Mu}$ tualidad. (Sentencia de 14 de octubre de 1976, Ar. 4.084).

\section{Secretarios: obligatoriedad de llevar la Secretaría DEl Juzgado de PAZ DE MENos dE 7.000 HaBitantes}

CONSIDERANDO: Que el fundamento aducido por el actor descansa en su apreciación de que al expresarse en tales preceptos, que vacante una Secretaría de Juzgado de Paz de menos de 7.000 habitantes, si no exis- 
ten peticionarios con el preferente derecho que les confiere el párrafo 1. del artículo 2.0 de la Ley citada, las plazas "podrán" ser desempeñadas por el Secretario del Ayuntamiento respectivo, se concede a estos Secretarios un derecho eventual y condicionado, del que podrán o no hacer libremente uso, y que como derecho subjetivo constituye una facultad, pero no una obligación que pueda ser impuesta coactivamente; interpretación errónea, pues la expresión en la Ley y Decreto mencionados de que a falta de peticionarios con derecho preferente los cargos "podrán" ser desempeñados por los Secretarios del Ayuntamiento respectivo, si bien significa que no es obligatoria su designación, como sucedería si se emplease la locución "serán» desempeñados, no confiere opción alguna al Secretario del Ayuntamiento, pues a quien concede la facultad de nombrar es al que corresponde el arbitrio para designarle o no, y si él es el designado, la obligación de desempeñar el cargo es tan inexcusable como para las demás personas en su caso nombradas, de las que igualmente que de aquéllos es correcto decir que "podrán desempeñar» los cargos, sin que ello esté en contradicción con que tendrán que ejercerlos si sobre ellos recae el nombramiento conforme a las normas que contienen los mencionados preceptos, y la única diferencia que existe a este respecto entre unos y otros es que los Secretarios de Ayuntamiento, simplemente por tener tal título, podrán ser designados, y para el nombramiento de las restantes personas - funcionarios de plantilla del Ayuntamiento, personas idóneas o funcionarios de la Justicia municipal próximos- es preciso cumplir los condicionamientos establecidos. (Sentencia de 22 de junio de 1976, Ar. 2.796).

\section{HACIENDAS LOCALES}

\section{ARbitrio de Plusvalía: explotación agrícola}

La más reciente y reiterada jurisprudencia del Tribunal Supremo, emanada de su Sala $3 .^{a}$, en consonancia con cuanto acaba de exponerse, tiene declarado que para estimar la existencia de una explotación agrícola o forestal, a los efectos de no sujeción al arbitrio, no basta con la -simple afección del terreno a un determinado cultivo o plantación, sino que es menester, además, que sus rendimientos guarden la debida proporción con la extensión de la finca y con el valor, sobre todo, que a la misma deba reconocerse (sentencia de 14 de febrero de 1972), pues explotación agrícola no significa lo mismo que finca rústica o cultivada, sino unidad de producción agraria en que se combinan diversos factores y solo uno de los cuales está constituido por la tierra, pero al que hay que agregar otros no menos importantes, como el de utilización de técnicas adecuadas y la tendencia a la producción de bienes proyectados al mercado, inclusive con el elemento complementario de determinado riesgo (sentencia del Tribunal Supremo de 28 de febrero de 1973), de tal suerte que, como ha venido a concluir el mismo Alto Tribunal (sen- 
- tencia de 22 de enero de 1974, con cita, a su vez, de las de 2 de marzo, 5 de abril, 25 de mayo, 4 y 6 de julio de 1973), no se da el meritado concepto de explotación agrícola si no se acredita - con carga de la prueba para quien invoque la existencia de la explotación- que los rendimientos de la finca gravada guardan la debida proporción con su valor en venta. (Sentencia de 15 de octubre de 1976, Ar. 4.204).

En la sentencia de 15 de noviembre de 1976 (Ar. 5.004) se dice que son muchas las sentencias coincidentes en afirmar que una cosa es el carácter de finca rústica y otra muy distinta la calificación como verdadera "explotación agrícola", de la misma manera que el artículo 24 de la Ley General Tributaria de 28 de diciembre de 1963 distingue en su artículo 72 entre "explotaciones» y meras "actividades económicas». $\mathrm{Y}$ así bien que no procede la exención del arbitrio si los rendimientos efectivos de la explotación agrícola o ganadera no guardan una razonable proporción con el valor en venta de la finca (sentencias de 28 de abril de 1969, 31 de octubre de 1970, 11 de marzo de 1971, 14 de febrero de 1972, 2 de marzo, 5 de abril, 4 y 6 de julio de 1973, 22 de enero de 1974 y 28 de febrero de 1976).

\section{CONTRIBUCIONES ESPECIALES: COSTO DE LAS OBRAS: INCLUSIÓN} DEL IMPORTE DE LAS EXPROPIACIONES

Considerando: Que en cuanto a la primera cuestión ha sido resuelta con reiteración por esta Sala en sus sentencias de 14 de junio, 24 de septiembre, dos de igual fecha 5 de diciembre de 1975, 15 de enero, 20 y 28 de febrero de 1976, entre otras, que sientan la doctrina de que cuando el artículo 454, 1, b), de la Ley de Régimen local se refiere al valor de los terrenos que las obras o instalaciones hubiesen de ocupar permanentemente, aunque pertenezcan al Ayuntamiento, siempre que aquéllos no fueran de uso público con anterioridad, cuyo valor es determinante del coste de las obras a incluir en las contribuciones especiales del artículo 451 y siguientes de la misma Ley, se comprende en dicho valor el importe de las expropiaciones de terrenos y edificios, ya que si el Ayuntamiento puede incluir el valor de sus propios terrenos, salvo los que fueran antes de uso público, con mayor razón ha de incluir las indemnizaciones satisfechas por las expropiaciones necesarias para realizar las obras, sin que este precepto específico de la citada Ley deje de aplicarse por efecto de lo que dispone la Ley del Suelo en sus artículos 115 a 120 , salvo que se haya seguido el sistema de compensación previsto en los mismos, lo que no sucede en el caso de litis. (Sentencia de 3 de julio de 1976, Ar. 3.591). 


\section{CoNTRIBUCIONES ESPECIALES: EXENCIÓN IMPROCEDENTE DEL BANCo HiPotecario dE ESPAÑA}

Considerando: Que la única cuestión que en la presente apelación se plantea consiste en precisar, en relación con las contribuciones especiales por obras de calzada y servicios complementarios de aceras a cargo del Banco Hipotecario de España como propietario de la finca número 10 del Paseo de Calvo Sotelo, en Madrid, el alcance del artículo 29 de la Ley número 13/1971, de 19 de junio, sobre organización y régimen del crédito oficial.

CONSIDERANDO: Que la exención en favor de los establecimientos gestores del crédito oficial tiene su fundamento en el carácter público de las funciones que desempeñan, nunca de superior jerarquía ni consideración que las del propio Estado, no siendo admisible, pues quebrantaría normas elementales del buen sentido, que si la exención no alcanza al propio Estado, cuando se trata de contribuciones especiales incluidas en los apartados $d), e), f), g$ ), $h$ ) y $k$ ) del artículo 469 , según claramente dispone el artículo $472, b$ ), de la Ley de Régimen local, gocen, en cambio, de exención organismos oficiales que no son de superior rango, siendo oportuno mencionar que en el expediente administrativo aparece en la relación de contribuyentes del lado Este del Paseo de Calvo Sotelo el Ministerio de Educación y Ciencia por los metros lineales de fachada que corresponden al Palacio de Bibliotecas y Museos, no siendo admisible, repetimos, que se conceda un trato de mayor favor al Banco Hipotecario de España. (Sentencia de 14 de junio de 1976, Ar. 2.804).

\section{POLICIA MUNICIPAL}

\section{ACTIVIdAdES MOLESTAS, INSALUBRES, NOCIVAS Y PELIGROSAS}

CoNSIDERANDO: Que argumenta con razón la sentencia apelada cuando dice que la regla del artículo $4 .^{\circ}$ del Decreto de 30 de noviembre de 1961 sobre ubicación y alejamiento de las industrias fabriles, regla que se completa, en el mismo plano normativo, con la del artículo 20 del mismo Reglamento $y$, en subordinación a estas normas, con la regla 11, apartado $3 .^{\circ}$, de la Instrucción de 15 de marzo de 1963, no es extensible a las actividades de almacenamiento, aunque tengan la calificación de peligrosas, porque, como dijimos en la sentencia de 30 de junio de 1965, aquel Reglamento (y la Instrucción) distingue las industrias fabriles o destinadas a un proceso de obtención o fabricación de productos y las actividades de almacenamiento y establece la norma de alejamiento fijada en los 2.000 metros, a contar del núcleo más próximo de población agrupada, de rigurosa excepcionalidad y condicionamiento siempre a la adopción de las medidas de máxima seguridad para la 
actividad fabril; distinción y precisión de la norma que pone de relieve el error de la Comisión Delegada de Saneamiento en cuanto sin otro motivo explícito que la opinión de que tal regla del artículo $4 .^{\circ}$ invocado alcanza a toda actividad peligrosa, propuso en el acto calificatorio de la actividad que se exigiera a la de almacenamiento de butano, de categoría 2.a, según su capacidad, a tenor de lo dispuesto en las Ordenes de 23 de marzo de 1961 y 17 de diciembre de 1966, el alejamiento que aquel artículo $4 .^{\circ}$ prevé, como regla general, para las industrias fabriles. (Sentencia de 11 de octubre de 1976, Ar. 5.126).

\section{LICENCIAS: OTORGAMIENTO POR ERROR: DECLARACION DE NULIDAD}

CONSIDERANDO: Que habiéndose impugnado la resolución municipal anulatoria de la licencia otorgada al recurrente para construir un edificio en la calle Corcubión de La Coruña, no es posible admitir la tesis de aquél acerca de la improcedencia radical de tal acuerdo porque, a tenor del artículo 172 de la Ley del Suelo y 16, número 2, del Reglamento de Servicios, no ofrece duda la posibilidad de acordar de oficio la anulación de las licencias otorgadas erróneamente, por supuesto sin necesidad de acudir a la declaración de lesividad, pues es ésta una potestad expresamente atribuida para lograr de modo más inmediato la rectificación de aquellos errores; será en consecuencia la real intervención de error en el otorgamiento lo decisivo a efectos de conocer la legitimidad del acto recurrido. (Sentencia de 6 de julio de 1976, Aranzadi 4.525).

\section{Licencias: Obra Sindical del Hogar y ARQuitectura}

CONSIDERANDo: Que dos problemas plantea la presente apelación: el relativo a la exención del pago de derechos y tasas por licencia de obras, solicitada por la Obra Sindical del Hogar y Arquitectura, y el de si es correcta, por razón de su cuantía, la liquidación girada por el Ayuntamiento de El Ferrol del Caudillo para la construcción de un grupo de 390 viviendas y 26 locales comerciales y urbanización en la Unidad Vecinal número 1 , Barrio $6 .^{\circ}$, del Polígono de Carranza.

Considerando: Que en la Ley de Régimen local no existe precepto general que establezca exención del pago de los derechos y tasas por prestación de servicios y sí, en cambio, por aprovechamientos especiales con el alcance que señala el artículo 439, con lo que bien se advierte que los derechos de licencia de obras a que se refiere el artículo 440, número 7 , de la Ley serán exigibles en los términos que al efecto establezca la correspondiente Ordenanza municipal, y si en ella se condiciona la exención en favor del Estado, la Provincia, el Municipio y las Mancomunidades y Agrupaciones de que el último forma parte 
a que las obras ase realicen directamente o por administraciónn, este requisito, que no es contrario a la Ley, tiene que ser inexcusablemente cumplido como ya ha declarado esta Sala en su sentencia de 19 de abril de 1976, y lo evidente que no se cumpla, cuando se celebra una subasta, cual en el presente caso, en que, como reconoce la entidad recurrente, la realización de las obras ha sido adjudicada a la empresa «Dragados y Construcciones».

CONSIDERANDo: Que así como los tipos de percepción de los derechos y tasas por aprovechamientos especiales no pueden exceder del valor del aprovechamiento, conforme al artículo 446 de la Ley de Régimen local, los tipos de percepción en los derechos y tasas por prestación de servicios se fijan teniendo en cuenta las circunstancias recogidas en el artículo 442, con posibilidad de recurso de alzada ante el Ministerio de Hacienda; por lo que no es posible sentar ahora la afirmación de que el tipo aplicado sobre el importe de las obras es contrario a la Ley, máxime cuando ha sido apliçada la bonificación del 90 por 100. (Sentencia de 11 de junio de 1976, Ar. 2.763).

\section{RUINA: CAUSAS PARA DEClaRARLA}

Las causas de declaración de estado ruinoso enumeradas en el artículo 170 de la Ley del Suelo no son entre sí complementarias en orden a producir el efecto jurídico referido, pues basta la constatación de una sola en el expediente contradictorio para que aquella declaración se ajuste a la normativa legal, como así lo hacen los actos municipales impugnados. (Sentencia de 12 de junio de 1976, Ar. 3.600).

\section{RUINA: CONCEPTO UNITARIO}

Considerando: Que robustece la tesis sustentada el acontecimiento de que la declaración de ruina total de un inmueble urbano es suficiente para dar lugar a ella, el que ésta se cristalice en una sola de sus plantas, lo que está reconocido y proclamado por la jurisprudencia de este Tribunal ad quem en sentencias de 24 de marzo y 4 de noviembre de 1958, 7 de febrero, 23 de abril y 28 de septiembre de 1959, 23 de septiembre y 24 de octubre de 1960,2 de junio y 26 de noviembre de 1962, 7 de marzo y 14 de octubre de 1963, 10 de mayo, 27 de noviembre y 27 de diciembre de 1965 y 12 de mayo de 1966, más las reflejadas en la decisión judicial atacada en esta apelación y posteriores, como la de 27 de febrero del corriente año, que sientan de manera general que «el concepto de edificio o casa ruinosa ha de reportarse unitario, salvo que existieran cuerpos de edificación independientes o aislados"; añadiéndose que: tal unidad existe, aunque partes más o menos extensas de la finca en litigio sean todavía buenas o estén en condiciones aisla- 
das de reparación, sin que sea necesario que estén en estado ruinoso todos sus elementos y dependencias, y que tan sólo de estar compuesto el inmueble de cuerpos de edificación independientes se puede declarar en estado de ruina uno o más de estos cuerpos, sin que ello afecte a sus demás componentes; por lo que el concepto de unidad es la regla general, y que el caso de la llamada ruina parcial de una finca urbana es un caso de existencia de distintos cuerpos aislados o independientes del resto edificado, con propia consistencia y propia utilidad independiente, pues de lo contrario no cabe hablar de ruina parcial. (Sentencia de 27 de septiembre de 1976, Ar. 4.716).

\section{Ruina: facultades del Ayuntamiento y de la Fiscalía DE LA VIVIENDA}

La intervención de la Fiscalía citada obedece a motivos de salubridad e higiene, artículo $1 .^{\circ}$ del calendado Decreto, mientras que la competencia del Excmo. Ayuntamiento de la capital de España no sólo obedece a este aspecto, sino muy especialmente a la custodia y defensa de la seguridad de los moradores de la casa y de los viandantes que discurren por los alrededores del inmueble de que se trate, competencia que le viene atribuida por el artículo 170 y concordantes de la Ley del Suelo, siendo ambas atribuciones y facultades uno de los supuestos de competencia concurrente, pero no excluyente, de ahi que la Fiscalia de la Vivienda ordenara reparaciones tendentes a la salubridad e higiene de los moradores de la casa litigiosa y, por el contrario, el Excmo. Ayuntamiento de Madrid declarara la ruina de dicho inmueble a la vista de una serie de obras necesarias en dicha casa y, en particular, a las circunstancias de hecho que rodean a la misma, declaración de ruina que interesa no sólo a los ocupantes de dicho edificio y viandantes que circulen por sus alrededores, sino muy especialmente a la comunidad interesada en que de dicho inmueble no se originen o puedan originarse riesgos para nadie. (Sentencia de 2 de octubre de 1976, Aranzadi 4.908).

\section{RUINA INMINENTE}

CONSIDERANDO: Que las excepcionales facultades que los números 1, in fine, y la del artículo 170 de la Ley del Suelo confieren al Ayuntamiento y al Alcalde, pueden ser considerados bien como reglamentación del ejercicio de potestades que genéricamente les otorga la Ley en situaciones especiales de grave peligro y urgencia, con raíz en los artículos $101, h), 117, b)$ y $d$ ), de la Ley de Régimen local y 1., 1, del Reglamento de Servicios, o bien - sin olvidar que pueda ser aquél su fundamento último- como configuración de una singular y específica actuación administrativa de aintervención de la Administración en la edifica- 
ciónn, pues tal es el epígrafe del Capítulo II, Título IV, de la Ley del Suelo, donde el artículo 170 se halla inserto, en la que al lado del estado de ruina normal contempla una específica situación de ruina en condiciones de peligrosidad y urgencia, sobre cuyo concepto la técnica constructiva ha elaborado y la jurisprudencia ha acogido el estado de ruina inminente, para cuya declaración se arbitra en el mismo precepto un sumario procedimiento no contradictorio, sino meramente informativo - como lo denomina la sentencia de esta Sala de 26 de diciembre de 1974-. Sea cualquiera la conceptuación jurídica que atribuyamos a esta actuación, lo evidente es que la legalidad del ejercicio de tan excepcionales facultades ha de insertarse rígidamente en el ámbito de las decisiones de urgencia o de inmediato peligro previsible con carácter de inminencia. Las medidas a adoptar por la autoridad competente deben ser perfectamente congruentes y guardar la proporcionalidad debida en función de la inminencia o inmediata del riesgo advertido. En la generalidad de los casos, para que la congruencia y proporcionalidad de la actuación material de la Administración en ejecución de los acuerdos adoptados está justificada aquella actuación material y debe realizarse sin pérdida de tiempo en plazo si no de horas al menos de días, como es obligada exigencia de las razones de urgencia motivadoras de tan excepcionales resoluciones. En otro caso carecería de sentido la infracción de trámites tan ineludibles normalmente, como el de audiencia de los interesados, sobre cuyos derechos pueden imponerse por esta vía sumaria tan irreparables limitaciones y aun sacrificios. (Sentencia de 19 de mayo de 1976, Ar. 2.889).

\section{SEGURIDAD SOCIAL AGRARIA}

\section{AyUNTAMIENTOS: EXENCIÓN}

CONSIDERANDo: Que la cuestión esencial que se nos plantea ante una exégesis de los preceptos rectores, aplicables al supuesto de autos - Ley de Bases de la Seguridad Social 193/1963, de 28 de diciembre; Texto articulado I de la anterior Ley, aprobado por Decreto 907/1966, de 21 de abril; Orden de 28 de diciembre de 1966; Ley 38/1966, de 31 de mayo, que estableció el Régimen Especial Agrario de la Seguridad Social, y Decreto 309/1967, de 23 de febrero, sobre Reglamento General de la anterior Ley-, llevada a efecto por esa Sala en sentencias de 9 de junio de 1970, 23 de marzo de 1971, 16 y 27 de diciembre de 1972, 5 de junio de 1973, 16 de enero, 4, 6 y 8 de abril, 29 de octubre, 5, 14 y 20 de noviembre de 1974, 19 de febrero y 9 de mayo de 1975, entre otras, que nos pone de manifiesto la inexistencia en el supuesto contemplado de los elementos condicionantes de la sujeción de la actora al pago de las cuotas empresariales de la Seguridad Social Agraria, fundada en la ausencia del requisito esencial derivado de la relación binómica empresatrabajador, para asignarle la cualidad de empresario, pues no realiza 
la explotación del predio de que es titular, en forma directa, como empresario agrícola, lo que da lugar a que se quiebre la precisa conjunción al no ostentar la condición de empresario, pues si bien tiene la titularidad de la finca no realiza por su cuenta actividad alguna de orden agrario, ni se ha acreditado la existencia de persona que trabaje por su cuenta, circunstancias que al no concurrir en la recurrente hacen que no se le pueda conceptuar como sujeto vinculado al pago de la cuota empresarial agraria, con la secuela lógica de acceder a la pretensión deducida, con devolución de las cuotas correspondientes, indebidamente satisfechas, declarando la nulidad del acuerdo por no estar ajustado a derecho. (Sentencia de 25 de junio de 1976, Ar. 3.866).

La sentencia de 11 de octubre de 1976 (Ar. 4.164) consigna en uno de sus Considerandos una doctrina similar diciendo:

CONSIDERANDo: Que ya es doctrina muy reiterada, en sentencias de este Tribunal Supremo, entre las que cabe citar las de 29 de octubre de 1964, 23 de marzo de 1971, 8 de abril de 1974, 28 de noviembre y 12 de diciembre de tal año, la de que con anterioridad a la aplicación de la Ley de 22 de diciembre de 1970, artículo 4. ${ }^{\circ}$, y Texto refundido de 23 de julio de 1971, artículo 44, se exigía, según la normativa precedente constituida por la Ley de 31 de mayo de 1966 y Reglamento de 23 de febrero de 1967, la concurrencia del carácter de empresario con trabajadores afectos a la explotación para que aquél pudiera ser configurado como sujeto pasivo de la cuota empresarial de la Seguridad Social Agraria por tratarse de un seguro obligatorio en el que es preciso se dé la concurrencia de empresario y trabajador; razones por las cuales en dicha doctrina interpretativa se vino negando la condición de empresario sujeto al pago de la cuota a las Corporaciones locales titulares de montes que no explotaban por sí y que, por tanto, carecían de personal a su servicio, sea fijo o eventual, afecto a esa explotación.

\section{TELEFONOS}

INSTALACIÓN AÉREA CON POSTES ENCLAVADOS EN VÍAS MUNICIPALES: COMPETENCIA

Considerando: Que entrando ya en el fondo del asunto litigioso consistente en la validez o nulidad de los acuerdos impugnados adoptados por la expresada Delegación del Gobierno, que implican a su vez la nulidad del acuerdo municipal de autorización condicionada de las instalaciones de cables telefónicos aéreos con soporte en terrenos municipales, fundamentalmente el litigio se centra en la cláusula municipal adicional a las generales, por la que se autoriza la instalación de postes y 
tendido aéreo a precario, condición que se impugnó por la Compañía Telefónica ante la Corporación municipal y por su desestimación tácita primero y expresa después determinó la intervención de la Delegación, que autorizó las instalaciones conforme al proyecto presentado por la Compañia concesionaria en su solicitud al Ayuntamiento, cuestión que determina la necesaria interpretación de la referida cláusula de precariedad, sobre la que ha declarado esta Sala en asuntos de absoluta identidad con el actual, que esta cláusula no puede interpretarse como la expresa reserva de una facultad revocatoria dependiente de la libre voluntad de la Corporación municipal que pueda en cualquier momento revocar su previa autorización, ya que a ello se opone la situación estatutaria derivada para la concesionaria de las disposiciones legales y administrativas que la regulan, pero que tampoco cabe desconocer la competencia municipal en materia urbanística, de tráfico e interés general del Municipio, pues, en definitiva, los derechos que se conceden a la Compañía Telefónica no pueden vulnerar esa competencia municipal para adoptar los acuerdos legalmente procedentes en cada caso, conforme a las normas legales y en especial a la Ley de Régimen local vigente, puesto que los derechos que otorga la base $6 .^{\text {a }}$ del Decreto de 31 de octubre de 1946 han de interpretarse en el contexto del ordenamiento jurídico patrio, que mantiene la vigencia de la aludida competencia municipal (sentencias de 16 de enero de 1975 y 25 de febrero de 1976, reiterando en parte la de la Sala 4..$^{a}$ de este Alto Tribunal de 29 de abril de 1970, cuya doctrina in extenso se da aquí por reproducida). $\mathrm{Y}$ es procedente declarar, como hizo el acuerdo recurrido, que tales modificaciones, a iniciativa del Ayuntamiento, serán costeadas por mitad entre éste y la Compañía Telefónica conforme a las citadas normas. (Sentencia de 13 de noviembre de 1976, Ar. 5.003).

\section{URBANISMO}

\section{Parcelaciones: Plan Parcial}

En principio, y en términos generales, la legitimación de las parcelaciones y reparcelaciones se apoya en un Plan Parcial. Ahora bien, esta exigencia establecida por la voluntad del legislador - aprobación anterior o simultánea de un Plan Parcial para poder llegarse a la parcelación o reparcelación y secuelas como normalización de fincas- no se puede admitir en términos estrictos y absolutos, pues la interpretación de los preceptos normativos en que así lo ordenan no puede ser tan rigurosa y sin exclusión alguna, esto último de concurrir acaecimientos pretéritos especialísimos que por las circunstancias que los rodean y constituir disposiciones de índole urbanística, integren en su contenido los requisitos esenciales que debe reunir un Plan Parcial, que por ello queda de no tener realidad jurídica el mismo por no ser creado, sea 
cualquiera que fuese la causa de esta falta, el estar subsumido en aquéllas, las que, en definitiva, vienen a sustituir con plena virtualidad, y en estas condiciones puede impulsarse las referidas parcelaciones y reparcelaciones y normalización de fincas; tal sucede ante la preexistencia de un Plan General, cuya eficacia directa, de no haber nacido con posterioridad un Plan Parcial derivado de aquél, contiene una reglamentación suficientemente detallada para que quede de manifiesto la existencia de la causa que motiva la reparcelación, haciendo innecesario en esta situación el Plan Parcial por producir los efectos propios del mismo; esta eficacia del Plan General sin el Parcial ha sido reconocida con carácter amplio por la jurisprudencia de este Alto Tribunal en otros aspectos (sentencias de 9 de febrero y 16 de diciembre de 1965, 17 de junio de 1966, 14 de febrero de 1967, etc.), y no se diga de tener realidad efectiva Ordenanzas que regulen de modo completo y preciso el uso de los terrenos, de tal modo que con la zonificación que figure en el Plan General (artículo 9. ${ }^{\circ}$, número 1, apartado a) y la referencia a las Ordenanzas permita conocer el volumen, destino y condiciones sanitarias y artísticas de las construcciones de cada zona (sentencias de 16 de diciembre de 1970, 4 de junio de 1971, 21 de diciembre de 1972, etc.); siendo de añadir que en todo caso el Plan Parcial debe ajustarse a las previsiones del General en funcionamiento, hasta el punto que al así reconocerlo este Tribunal afirma que de no suceder de esta forma se incurriría en nulidad (sentencias de 26 de mayo de 1958, 14 de octubre de 1961, 12 de febrero de 1962, 17 de marzo de 1963 y 16 de abril de 1974); y obvio es que, por lo argumentado, no hay razón alguna para que esta doctrina jurisprudencial no sea aplicable al supuesto concreto de la reparcelación; si del propio Plan General, tal como se encuentra la zonificación, ya resulta evidente la injusta y desproporcionada distribución de los beneficios y cargas de la ordenación, pues entonces surge la posibilidad de instar la reparcelación al amparo de la causa del artículo 77, número 2, apartado b), de la Ley de Régimen del Suelo, o si el Plan General desciende tan al detalle que contiene una configuración de las parcelas de una zona, en este caso cabe intentar la reparcelación al amparo de la causa a) del mismo párrafo y artículo. (Sentencia de 4 de junio de 1976, Ar. 4.060).

\section{PROYECTO DE URBANIZACIÓN: DOCUMENTOS INTEGRANTES DEL EXPEDIENTE}

Considerando: Que acorde con esta exigencial formal, el expediente en que se contiene el Proyecto de reparcelación del Polígono Los Frates, de Cáceres, que el Ayuntamiento de esta ciudad acordó redactar de oficio, después de haber asumido la iniciativa de esta actuación al amparo del artículo 80 , número 2 , de la Ley sobre Régimen del Suelo y Ordenación Urbana, debió integrarse con los documentos que señala el artículo 20 del Reglamento de Reparcelación. Estos documentos, por 
tener el carácter de documentos públicos, requieren, por imperativo mandato del artículo 1.216 del Código civil y de su propia esencia, su autorización por el funcionario público competente con las solemnidades requeridas por la Ley. En este caso su refrendo corresponde al Ayuntamiento de Cáceres, personificado por sus órganos y Secretario fedatario de la Corporación en la órbita de sus respectivas atribuciones, quienes de este modo se responsabilizarán, autorizándola, de la programación técnica y de los estudios y conclusiones de este carácter elaborados por el equipo de profesionales técnicos, a quienes se había confiado la preparación del Plan en uso de la facultad que a la Corporación le confiere el artículo 24, 3, de la Ley del Suelo, pero bien entendido que en estos supuestos es tan sólo la elaboración y preparación la que corresponde hacer a los técnicos desginados, pero la redacción y efectiva formulación del Plan o Proyecto es de la indeclinable competencia del Ayuntamiento, responsable de su iniciativa a través de sus órganos de actuación. (Sentencia de 14 de mayo de 1976, Ar. 2.777).

\section{Planes: su obligatoriedad}

Considerando: Que el discernimiento de la cuestión de fondo latente en el pleito y atinente a la verificación del acto concesional de una licencia de obras, cuyo carácter reglado es notorio, demanda la previa formulación de unas breves precisiones jurídicas en orden a los principios fundamentales que informan el régimen urbanístico en materia de edificación y la trascendencia que revisten los Planes de Ordenación urbana, debiendo, a tal efecto, hacer notar que tales previsiones, así como, los proyectos de urbanización, de vigencia indefinida, según el artículo 36 de la Ley del Suelo, y de ejecutividad inmediata, una vez publicada su aprobación definitiva (artículo 44), resultan imperativas tanto para la Administración como para los administrados, pues en todo caso están sujetos aal cumplimiento de las disposiciones sobre ordenación urbana contenidas en la presente Ley y en los Planes, Proyectos, Normas y Ordenanzas aprobadas con arreglo a la misma” (artículo 45); reputándose nulas cualesquiera reservas de dispensación que se concedieren, salvo que lo fuesen para edificios monumentales o singulares, de conformidad con lo dispuesto en el apartado $1 .^{\circ}$ del artículo 46 , de idéntico texto legal, precepto que, en su párrafo $2 .^{\circ}$, prevé la posibilidad de que, en casos concretos y excepcionales, se modifique el régimen institutido con carácter general por los Planes y Proyectos en sectores urbanos determinados y de reserva urbana mediante la formación de un Plan y Normas que definan las posibilidades de edificación, utilizaciones especiales, creación y conservación de espacios libres, determinación de perímetros o de lugares afectos, pero estos Proyectos de modificación (apartado 3. $)$ han de someterse a información pública por plazo de un mes y requerirán «la aprobación de la Corporación municipal, con el quórum especial del artículo 303 de la Ley de Régimen lo- 
cal, y de la Comisión provincial o central de Urbanismo, según procediere», quedando, mientras tanto, vigente la aludida imperatividad de los Planes de Ordenación urbana, pues, como enseña el artículo 47 de la tan repetida Ley del Suelo, el uso de los predios no puede apartarse del destino previsto y las nuevas construcciones han de ajustarse a la ordenación aprobada. (Sentencia de 27 de septiembre de 1976, Ar. 5.123).

NEMESIO RODRÍGUEZ MORO 